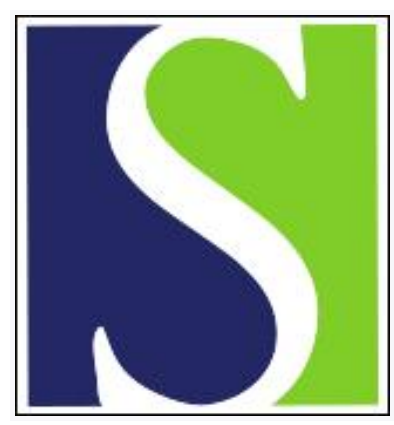

Scand J Work Environ Health 1992;18(6):403-407

https://doi.org/10.5271/sjweh.1556

Issue date: 01 Dec 1992

Possible mechanisms of formaldehyde-induced discomfort in the upper airways.

by Wilhelmsson B, Holmstrom $M$

Affiliation: Department of Oto-Rhino-Laryngology, Vasteras Central Hospital, Sweden.

This article in PubMed: www.ncbi.nlm.nih.gov/pubmed/1485166

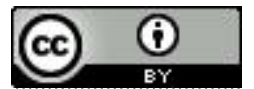




\title{
Possible mechanisms of formaldehyde-induced discomfort in the upper airways
}

\author{
by Bo Wilhelmsson, MD, ${ }^{1}$ Mats Holmström, $\mathrm{MD}^{2}$
}

\begin{abstract}
WILHELMSSON B, HOLMSTRöM M. Possible mechanisms of formaldehyde-induced discomfort in the upper airways. Scand $J$ Work Environ Health 1992;18:403-7. Occupational exposure to formaldehyde often causes nasal discomfort. The objective of this study was to determine whether chronic exposure to formaldehyde causes annoying symptoms by direct irritation and whether it affects all exposed people (through hyperreactivity in atopic persons, through formaldehyde-induced hyperreactivity also in nonatopic persons, or through an immunologically mediated, immediate type 1 reaction to formaldehyde itself). It was found that about $50 \%$ of the studied population of 66 workers occupationally exposed to formaldehyde during formaldehyde production experienced nasal discomfort through hyperreactivity. Atopics were not significantly overrepresented among the persons with occupational nasal symptoms. Two workers with isolated occupational nasal discomfort, and sensitized by long-term inhalation, had a positive radioallergosorbent test for formaldehyde. The conclusion was reached that exposure to formaldehyde should be minimized as much as possible for all people, not only for atopic persons.
\end{abstract}

Key words: allergy, atopy, hyperreactivity, nose.

Formaldehyde is not only a problem in occupational environments; it can also be troublesome in indoor climates in general. Since 1980, when it was first recognized that formaldehyde could act as a carcinogen in rats (1), epidemiologic studies of its carcinogenic effects have been performed, with somewhat divergent results $(2,3)$. However, one outcome of this discussion has been that the interest in other effects of formaldehyde has increased. Acute effects have occurred, and it has been reported that formaldehyde is a skin sensitizer and may give rise to acute distress symptoms of the eyes, upper airways, and, in a high concentration, lower airways (4-7). Few data are available, however, concerning the mechanisms of the observed symptoms, and a need for studies of the long-term effects of formaldehyde has been pointed out by several authors $(5,8)$.

In previous studies we have investigated histological effects of formaldehyde and the upper respiratory airway symptoms which it causes. We found that histological metaplasia was significantly more pronounced in workers exposed to formaldehyde for a long period of time (9) and that many of the exposed workers had substantial, perennial nasal complaints which, to a high degree, were associated with their place of work. Nasal obstruction and discharge, especially the former, were the most troublesome nasal complaints. The majority of the workers reported distinct improvement during

1 Department of Oto-Rhino-Laryngology, Västerás Central Hospital, Västerås, Sweden.

2 Department of Oto-Rhino-Laryngology, Huddinge University Hospital, Huddinge, Sweden.

Reprint requests to: Dr BJ Wilhelmsson, Department of OtoRhino-Laryngology, Västerás Central Hospital, S-721 89 Västerås, Sweden. weekends and holidays. The frequency of discomfort in the lower airways and eyes also differed significantly between the exposed workers and the reference group (10).

The objective of the present study was to investigate the mechanisms underlying the symptoms, especially nasal ones, in chronically exposed workers. Possible causes considered were direct irritation by formaldehyde, affecting anyone, hyperreactivity in atopics, formaldehyde-induced hyperreactivity also in nonatopics, and an immunologically mediated type 1 reaction to formaldehyde itself. In this context nonspecific hyperreactivity is nasal symptoms caused by various irritants such as strong odors, smoke, and other kinds of air pollution (11). If we were able to distinguish risk factors, we might be able to prevent the development of airway problems in certain individuals in formaldehyde-exposed environments.

\section{Subjects and methods}

All of the investigations were conducted on subjects selected cross-sectionally. No one refused to participate. The studied environment was a formaldehydeproducing plant with 66 employees, all exposed almost exclusively to formaldehyde in a fairly stable manner (the formaldehyde group). This formaldehyde-exposed group consisted of 59 men and 7 women, of whom 24 $(36 \%)$ were smokers. The mean age of the formaldehyde group was 38.0 years, and their mean duration of formaldehyde exposure was 10 (range $1-36$ ) years. Thirty-six community clerks, 20 men and 16 women, served as the reference group. Ten of them (28\%) were smokers, and the mean age of the whole reference group was 39.9 years. They were not exposed to any industrial solvents or dust. 
The formaldehyde concentration was measured with personal sampling equipment in the ambient air of all the workers' worksites. Sampling tubes (Amberlite XAD-2) were used, and the samples were analyzed by high-performance liquid chromatography, as earlier described (9). In the formaldehyde group the formaldehyde concentration was between $0.05-0.6$ (mean $0.26) \mathrm{mg} \cdot \mathrm{m}^{-3}$. For the reference group the mean formaldehyde exposure value, based on several measurements over the year, was $0.09 \mathrm{mg} \cdot \mathrm{m}^{-3}$. The formaldehyde group was not exposed to other chemicals to any important extent; repeated measurements of exposure to phenol, ammonia, epichlorhydrin, methanol, and ethanol were found to be less than $1 \%$ of their Swedish occupational exposure limits.

The subjects answered a specially designed questionnaire from which information was obtained concerning nasal, lung, and eye symptoms, especially atopic constitution and history of mucosal hyperreactivity in the airways and eyes, and detailed information was requested about dermatological symptoms such as itching, uticaria, and eczema.

Phadiatop ${ }^{\circledR}$, an in vitro test for predicting atopy (Pharmacia Diagnostics AB, Uppsala, Sweden), was used. Phadiatop ${ }^{\circledR}$ is a laboratory test based on the allergosorbent principle. It utilizes a paper disc which carries a balanced mixture of 10 relevant allergens causing common inhalant allergy. A blood sample of

Table 1. Symptoms experienced by the formaldehyde-exposed workers and the reference group of clerks.

\begin{tabular}{|c|c|c|c|c|}
\hline & \multirow{2}{*}{$\begin{array}{c}\text { Form- } \\
\text { aldehyde } \\
\text { group } \\
(N=66) \\
(\%)\end{array}$} & \multirow{2}{*}{ 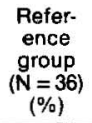 } & \multicolumn{2}{|c|}{ Rate difference } \\
\hline & & & $\begin{array}{l}\text { Per- } \\
\text { cent }\end{array}$ & $95 \% \mathrm{Cl}$ \\
\hline General nasal discomfort & 67 & 25 & 42 & $24-60$ \\
\hline $\begin{array}{l}\text { Workplace-related riasal } \\
\text { discomfort }\end{array}$ & 53 & 3 & 50 & $37-63$ \\
\hline $\begin{array}{l}\text { General lower airway } \\
\text { discomfort }\end{array}$ & 44 & 14 & 30 & $14-47$ \\
\hline $\begin{array}{l}\text { Workplace-related low } \\
\text { airway discomfort }\end{array}$ & 33 & 3 & 28 & $15-40$ \\
\hline General eye discomfort & 24 & 6 & 18 & $6-36$ \\
\hline General skin discomfort & 36 & 11 & 25 & $10-41$ \\
\hline
\end{tabular}

$200 \mu \mathrm{l}$ is sufficient to perform an assay. The results are reported as positive or negative, indicating whether the person's symptoms are probably due to an allergy to common inhalant allergens or not (12).

The serum level of immunoglobln (total $\mathrm{IgE}$ ) was measured by the Phadebas paper radioimmunosorbent test (Prist, Pharmacia Diagnostics AB, Uppsala, Sweden) at the Clinical Chemical Laboratory of Huddinge Hospital, Sweden.

Epicutaneous tests were performed with a $1 \%$ formaldehyde solution on a paper disc covered by surgical plaster (Finn Chamber ${ }^{\circledR}$, Epitest Oy, Helsinki, Finland). The test person was asked not to wash the area before the results were noted. Two different readings were made, the first after $20 \mathrm{~min}$ and the second after $72 \mathrm{~h}$. In the latter case the test person had taken away the disc after $48 \mathrm{~h}$.

The collected sera were analyzed for IgE antibodies to formaldehyde by the radioallergosorbent test (RAST) (13), using formaldehyde hapten discs (Pharmacia Diagnostics AB, Uppsala, Sweden). Each serum sample was tested in quadruplicate against formaldehyde-human serum albumin (FA-HSA), using human serum albumin (HSA) alone as a control for the nonspecific binding of IgE. The ratio of FA-HSA to HSA was calculated. A ratio of less than 2.0 was regarded as negative.

To analyze the answers to the questionnaire, rate difference [with the $95 \%$ confidence interval $(95 \% \mathrm{CI})$ ] and a chi-square test based on a binomial model or Fisher's exact test were used. The differences were classified as significant if the P-value was $<0.05$.

\section{Results}

From the questionnaire it was found that $67 \%$ of the formaldehyde group had general nasal discomfort problems, which in this context meant that the symptoms were not solely restricted to the occupational environment. The corresponding proportion for the reference group was $25 \%(\mathrm{P}<0.001)$ (table 1$)$.

Nasal discomfort, strictly connected to the workplace, occurred in $53 \%$ of the formaldehyde group and in $3 \%$ of the reference group $(\mathrm{P}<0.001)$ (table 1$)$.

Table 2. Dermatological findings in workers occupationally exposed to formaldehyde and in a reference group of clerks and the rate difference between the formaldehyde-exposed groups and their corresponding reference groups. $(95 \% \mathrm{Cl}=95 \%$ confidence interval)

\begin{tabular}{|c|c|c|c|c|c|c|c|c|c|c|c|c|}
\hline \multirow{3}{*}{$\begin{array}{l}\text { Dermatological } \\
\text { finding }\end{array}$} & \multicolumn{3}{|c|}{ Formaldehyde group } & \multicolumn{3}{|c|}{ Reference group } & \multicolumn{6}{|c|}{ Rate difference between the groups } \\
\hline & \multirow{2}{*}{$\begin{array}{c}\text { Atopics } \\
(\mathrm{N}=7) \\
(\%)\end{array}$} & \multirow{2}{*}{$\begin{array}{c}\text { Non- } \\
\text { atopics } \\
(\mathrm{N}=59) \\
(\%)\end{array}$} & \multirow{2}{*}{$\begin{array}{c}\text { All } \\
(N=66) \\
(\%)\end{array}$} & \multirow{2}{*}{$\begin{array}{c}\text { Atopics } \\
(N=12) \\
(\%)\end{array}$} & \multirow{2}{*}{$\begin{array}{c}\text { Non- } \\
\text { atopics } \\
(\mathrm{N}=24) \\
(\%)\end{array}$} & \multirow{2}{*}{$\begin{array}{c}\text { All } \\
(N=36) \\
(\%)\end{array}$} & \multicolumn{2}{|c|}{ Atopics } & \multicolumn{2}{|c|}{ Nonatopics } & \multicolumn{2}{|c|}{ All } \\
\hline & & & & & & & Percent & $95 \% \mathrm{Cl}$ & Percent & $95 \% \mathrm{Cl}$ & Percent & $95 \% \mathrm{Cl}$ \\
\hline $\begin{array}{l}\text { Skin dis- } \\
\text { comfort }\end{array}$ & 14 & 39 & 36 & 17 & 8 & 11 & -3 & $-35-31$ & 31 & $14-47$ & 25 & $10-41$ \\
\hline $\begin{array}{l}\text { Positive imme- } \\
\text { diate reaction } \\
\text { in the form- } \\
\text { aldehyde skin } \\
\text { test }\end{array}$ & 14 & 2 & 3 & 8 & 0 & 3 & 6 & $-24-36$ & 2 & - & 0 & $-6-7$ \\
\hline $\begin{array}{l}\text { Positive de- } \\
\text { layed reaction }\end{array}$ & 14 & 17 & 17 & 0 & 4 & 3 & 14 & - & 13 & $0-25$ & 14 & $3-24$ \\
\hline
\end{tabular}


In the Phadiatop test, the frequency of atopics was found to be $11 \%$ in the formaldehyde group and $33 \%$ in the reference group, the rate difference being $-22 \%$ $(95 \%$ CI $-40--6 \%)$.

The relative frequency of atopics among the workers of the formaldehyde group with nasal problems was $11 \%$, and among those without nasal problems it was $9 \%$. Thus these figures did not deviate from the mean value of $11 \%$ in the entire formaldehyde group.

In the reference group the frequency of atopics among the persons with general nasal symptoms was $56 \%$ and among those without nasal problems $26 \%$, the rate difference being $30 \%(95 \% \mathrm{CI}-7-66 \%)$. When the nonatopic subjects with general nasal discomfort in the formaldehyde group $(66 \%)$ were compared with nonatopics in the reference group (17\%), the rate difference was $49 \%(95 \%$ CI $30-69 \%$, $\mathrm{P}<0.001)$.

The same analyses as above were carried out concerning discomfort from the sinus and throat, but no significant results were found.

In the formaldehyde group $44 \%$ reported general lower airway discomfort as intermittent cough, wheezing, or symptoms of chronic bronchitis. The corresponding frequency in the reference group was $14 \%$ $(\mathrm{P}<0.01)$ (table 1$)$. For lower airway symptoms connected with the workplace, $33 \%$ of the formaldehyde group had a positive case history, while one person in the reference group had such problems, caused by hypersensitivity to mites in a carpet (table 1). Only 7\% of the workers with lower airway problems in the formaldehyde group were atopics, according to the Phadiatop test, while this figure in the reference group was $40 \%$, the rate difference being $-33 \%$ (95\% CI $-77-10 \%$ ).

In the formaldehyde group, $24 \%$ had general eye problems. This frequency can be compared with the figure of $6 \%$ in the reference group $(\mathrm{P}<0.05)$ (table 1$)$. The frequency of eye discomfort related to the place of work was $20 \%$ in the formaldehyde group. None of the subjects of the reference group had eye symptoms related to work.

Thirty-six percent of the formaldehyde-exposed workers had dermatological problems such as eczema or itching, while the corresponding frequency among the reference group was $11 \%$ (table 1). Concerning nonatopics and skin discomfort, it was found that $39 \%$ of the formaldehyde group suffered from annoying dermatological symptoms, while the figure for the reference group was $8 \%$, the rate difference being $31 \%$ (95\% CI 14-47\%, P<0.01).

In the epicutaneous test of the formaldehyde group, $3 \%$ had a positive immediate reaction after $20 \mathrm{~min}$. Furthermore, $17 \%$ had a positive delayed skin reaction after $72 \mathrm{~h}$ (table 2). There were four strong dermatological reactions with vesicles $(+++)$, two cases of redness and swelling $(++)$, and five cases of redness of the skin $(+)$. In the reference group there was one person with a positive immediate reaction and an- other one with a positive delayed reaction (table 2 ).

In the formaldehyde group one of the seven atopics had dermatological problems. Two of the 12 atopics in the reference group had skin symptoms (table 2).

Forty percent of the 15 subjects with positive skin tests from the two groups had clinical dermatological symptoms. Among the 13 workers exposed occupationally to formaldehyde, and with positive skin tests, three felt a clear connection between the skin problems and the work environment. Furthermore, 92\% of the 13 formaldehyde-exposed workers with positive skin tests had clinical symptoms of the nose or the lower airways.

Two cases with a positive formaldehyde-RAST were found after prolonged exposure to formaldehyde by inhalation. The FA-HSA:HSA ratio being 2.7 and 25.1. Both of these workers had high total IgE values, 177 and $360 \mathrm{kU} / \mathrm{I}$, and belonged to the formaldehyde group. One of them, aged 50 years, had severe rhinitis which was clearly associated with the workplace, but he had no history of atopy. However, his Phadiatop test was positive. The other man, aged 55 years, with the higher FA-HSA:HSA ratio, was a supervisor of formaldehyde production and often examined samples of formaldehyde, when he was sometimes exposed to high concentrations of airborne formaldehyde. He had been exposed to formaldehyde for 14 years by inhalation, and he had nasal and skin symptoms that were definitely associated with the workplace. His skin tests with formaldehyde were negative concerning the immediate reaction, but positive for the delayed response. Furthermore, he had a positive history of atopy and his Phadiatop test was positive. There were no significant findings regarding the total IgE values in relation to symptoms from the upper or lower airways, nor from the eyes and skin.

\section{Discussion}

The questionnaire data confirmed that in certain environments formaldehyde is an important occupational health problem with regard to the upper and lower airways and the skin.

The frequency of atopics in the formaldehyde-exposed group could be considered low, but in the reference group it was possibly high. The prevalence of atopy has been calculated to be about $30 \%$ in Scandinavia and Great Britain (44). Our findings could mean that a certain number of atopic individuals had left the formaldehyde-exposed environment.

Among the atopic persons, identified by a positive Phadiatop test, we found no significant overrepresentation of clinical symptoms from the upper or lower airways, either from the eyes or the skin, in the workers exposed to formaldehyde. This finding is not in accordance with the general belief that atopic persons are more prone to develop clinical symptoms in many occupational environments. This concept does not seem to be relevant for formaldehyde, however, as 
about half of the exposed population developed nasal hyperreactivity anyhow.

One result of our investigations is thus that formaldehyde in moderate doses can provoke nasal hyperreactivity in about $50 \%$ of a population subjected to long-term exposure, according to the concept that hyperrreactivity means significant nasal discomfort (mainly nasal obstruction) in an environment in which not all exposed people feel annoying symptoms and when allergic mechanisms can be ruled out (eg, by means of the Phadiatop test used in this study).

Thus our results indicate that formaldehyde seems to induce nonspecific hyperreactivity in the airways outside the workplace also, according to our figures for nonspecific hyperreactivity in nonatopics. This result is in line with the findings by Bernstein et al (5) in their studies of the lower airways and formaldehydeinduced bronchial hyperreactivity.

Another observation was that many of the formaldehyde-exposed workers with dermatological problems also had airway symptoms. The significance of positive dermatological findings in the skin testing when symptoms only occur from the airways is still being debated. The cases of formaldehyde skin sensitization in the reference group could be a result of cosmetic use among females.

As early as 1934, Horsefall (15) showed, in an experimental study on humans, that the inhalation of formaldehyde gas still produced cutaneous reactions when the possibility of local contact had been ruled out.

The most interesting observation concerning the hypothesis of IgE-mediated sensitization to formaldehyde leading to nasal symptoms was made in two cases, heavily exposed to formaldehyde by the respiratory route. These two cases indicated that long-term inhalation exposure to formaldehyde might cause sensitization and trigger a classical IgE-mediated allergy in the nose of atopic individuals in certain environments (16),

Pattersson et al (17) reported on two nurses with formaldehyde-induced asthma and IgE antibodies against FA-HSA. However, their sera were nearly as reactive to $\mathrm{HSA}$ alone, a finding indicating that the IgE antibodies were specific for denatured and modified HSA in general. From their published data, we have calculated their FA-HSA:HSA ratio to be less than 2.0.

Nordman et al (18) concluded that asthma-like respiratory symptoms can be caused by specific sensitization to formaldehyde. In their study they estimated that this mechanism was operative in $5 \%$ of the persons exposed to formaldehyde, and furthermore they demonstrated that $31 \%$ of these persons had bronchial hyperreactivity. They concluded that formaldehyde-induced asthma, though apparently a rare disease, was underreported. In addition, they considered that low domestic exposure can maintain symptoms in individuals already sensitized.
The explicit answers to our initial questions are that, in certain circumstances, formaldehyde can induce an IgE-mediated type 1 reaction in the nose, but, in most cases the annoying nasal symptoms are caused by formaldehyde-induced hyperreactivity, which can cause problems in about $50 \%$ of a population exposed to formaldehyde at the levels described in this paper. These levels are not extremely high, but could exist outside occupational environments, a finding which is perhaps the most interesting. Another finding was that atopics run approximately the same risk of suffering from this hyperreactivity as nonatopics.

\section{Acknowledgments}

We wish to thank $\mathrm{G}$ Rosén, $\mathrm{PhD}$, and his staff at the Swedish National Board of Occupational Safety and Health for the exposure analyses. We also want to thank S Sörensen, PhD, at the Research Unit of the Central Hospital, Västerås, for his help with statistical and epidemiologic matters. This investigation was supported financially by the Swedish Work Environment Fund (project 81-0313).

\section{References}

1. Swenberg JA, Kerns WD, Mitchell RE, Gralla EJ, Pavkov RL. Induction of squamous cell carcinomas of the rat nasal cavity by inhalation exposure to formaldehyde vapour. Cancer Res 1980;30:3398-402.

2. Blair A, Stewart P, O'Berg M, Gaffey W, Walrath J, Ward J, et al. Mortality among industrial workers exposed to formaldehyde. J Natl Cancer Inst 1986;76: 1071-84.

3. Olsen JH, Asnaes S. Formaldehyde and risk of squamous cell carcinoma of the sino-nasal cavities in humans. Br J Ind Med 1986;43:769-74.

4. Andersen I. Formaldehyde in the indoor environment - hospital health implications and the setting of standards. In: Fanger, PO, Valbjorn O, ed, Indoor climate effects on human comfort, performance and health in residential, commercial and light-industry buildings: proceedings of the first international indoor climate symposium. Copenhagen: Danish Building Research Institute, 1979:65-87.

5. Bernstein RS, Stayner LT, Elliot LJ, Kimbrough R, Falk $\mathrm{H}$, Blade L. Inhalation exposure to formaldehyde: an overview of its toxicology, epidemiology, monitoring and control. Am Ind Hyg Assoc J 1984;45(11):778-85.

6. Gibson JE, ed. Formaldehyde toxicity. Washington, DC: Hemisphere Publishing Corporation, 1983:175-97.

7. National Research Council (NRC). Formaldehyde - an assessment of its health effects. Washington, DC: Committee on Toxicology, National Academy of Sciences, 1980.

8. Report on the consensus workshop on formaldehyde. Environ Health Perspect 1984:58:323-81.

9. Holmström M, Wilhelmsson B, Hellquist H, Rosén G. Histological changes in the nasal mucosa in persons occupationally exposed to formaldehyde alone and in combination with wood dust. Acta Otolaryngol (Stockh) 1989;107:120-9.

10. Holmström M, Wilhelmsson B. Respiratory symptoms and pathophysiological effects of occupational exposure to formaldehyde and wood dust. Scand J Work Environ Health $1988 ; 14: 306-11$.

11. Wihl JÅ. Assessment of nasal hyperreactivity [hyperactivity]. Malmö (Sweden): University of Lund, 1986. 
12. Herold DA, Duyan I, Kunkel G. Phadiatop versus Gesamt- IgE. Eine vergleichende Untersuchung über die Effizienz zweier Screening-Methoden in der Allergiediagnostik Teil II. Allergologie 1987:10;300-3.

13. Wide L, Bennich $\mathbf{H}$, Johansson SG0. Diagnosis of allergy by an in-vitro test for allergen antibodies. Lancet 1967;2:1105- 7 .

14. Mygind N. Genetics and prevalence of atopic allergy. In: Mygind N, ed. Nasal allergy, Oxford: Blackwell Scientific Publications, 1978:105.

15. Horsefall F. Formaldehyde hypersensitiveness: an experimental study. J Immunol 1934;27:569-81.

16. Wilhelmsson B, Holmström M. Positive formaldehyde-
RAST after prolonged formaldehyde exposure by inhalation. Lancet 2:1987;164.

17. Patterson R, Pateras V, Grammer LC, Harris KE. Human antibodies against formaldehyde-human serum albumin conjugates or human serum albumin in individuals exposed to formaldehyde. Int Arch Allergy Appl Immunol 1986;79:53-9.

18. Nordman H, Keskinen H, Tuppurainen, M. Formaldehyde asthma - rare or overlooked? J Allergy Clin Immunol 1985;75:91-9.

Received for publication: 3 October 1990 